\title{
Assessing Partnership Alternatives in an IT Network Employing Analytical Methods
}

\author{
Vahid Reza Salamat, ${ }^{1}$ Alireza Aliahmadi, ${ }^{1}$ Mir Saman Pishvaee, ${ }^{1}$ and Khalid Hafeez $^{2}$ \\ ${ }^{1}$ Socio-Economic Systems Engineering Department, Iran University of Science and Technology, Tehran, Iran \\ ${ }^{2}$ Business \& Management Division, Dundee Business School, University of Abertay, Bell Street, Dundee DD1 1HG, UK
}

Correspondence should be addressed to Alireza Aliahmadi; alireza@iust.ac.ir

Received 13 June 2016; Revised 1 September 2016; Accepted 15 September 2016

Academic Editor: Junhu Ruan

Copyright (C) 2016 Vahid Reza Salamat et al. This is an open access article distributed under the Creative Commons Attribution License, which permits unrestricted use, distribution, and reproduction in any medium, provided the original work is properly cited.

\begin{abstract}
One of the main critical success factors for the companies is their ability to build and maintain an effective collaborative network. This is more critical in the IT industry where the development of sustainable competitive advantage requires an integration of various resources, platforms, and capabilities provided by various actors. Employing such a collaborative network will dramatically change the operations management and promote flexibility and agility. Despite its importance, there is a lack of an analytical tool on collaborative network building process. In this paper, we propose an optimization model employing AHP and multiobjective programming for collaborative network building process based on two interorganizational relationships' theories, namely, (i) transaction cost theory and (ii) resource-based view, which are representative of short-term and long-term considerations. The five different methods were employed to solve the formulation and their performances were compared. The model is implemented in an IT company who was in process of developing a large-scale enterprise resource planning (ERP) system. The results show that the collaborative network formed through this selection process was more efficient in terms of cost, time, and development speed. The framework offers novel theoretical underpinning and analytical solutions and can be used as an effective tool in selecting network alternatives.
\end{abstract}

\section{Introduction}

Business networks have become an essential part of conducting business. This is because the nature of business environment has changed and in many industries strategic business networks are replacing market structure theories $[1,2]$. As a consequence of increased global competition, technological complexities, and environmental uncertainties, the firms could not internally perform all of the value creation activities, and instead they create strategic collaborations and interfirm ties to focus on their core competencies by externalizing some of the value creation activities to other network actors [3]. The significance of the concept leads to many efforts from the authors in various disciplines and provides a huge body of knowledge in different branches of science like management, economy, computer science, industrial engineering, sociology, law, and so forth, with various keywords like "collaborative network" [4], "collaborative networked organization" [5], "strategic networks" [1], "relational view" [6], "business networks" [7], "network approach to strategic management" [2], and "industry network approach" $[8,9]$. This diversity of literature convinced the authors [10] to provide a metareview in different types of interorganizational relationships. This diversity of literature is because we are in the preparadigmatic phase, as Kuhn named it, of interpreting this phenomenon which is sometimes called a new discipline [4]. There are some debates on the economic reason of this paradigm shift; [11] named the innovation economy and growth of information technology as the reason behind decentralization of firms and emergence of business ecosystems.

Firms exploit interorganizational relationships for a number of reasons. According to [12] there are four motives to these: (1) acquiring resources, (2) reducing uncertainties, (3) enhancing legitimacy, and (4) attaining collective goals. Gulati et al. [1] argue that a firm's network could be a source 
of competitive advantages, because the firm's network is idiosyncratic, inimitable, and nonsubstitutable, and it could be a source of sustainable competitive advantage based on resource-based view of firms. In addition, these networks could provide some benefits for firms like learning, achieving economies of scale and scope, and providing access to information, resources, markets, and technologies. Moreover, firms can share their risks through these relations and [12] and increase the agility. On the other hand, the networks may have a negative impact on the firm's performance and could lead to some constraints like "lock-in and lock-out" effect which occurs because of resource constraints, and also loyalty expectation of partners. As a result, a specific relationship may preclude organizations from relating to some other networks $[1,13]$.

In addition, strategic networks may have major influence on customers and/or end users. A network may combine resources and capabilities to deliver unique products or services to customers, and this is the outcome of a complex value activity integration process. Similarly, any failure or ineffectiveness would be transferred to customers, thereby progressively ruining the competitive advantage of the entire network. Moreover, the formation of a collaborative network is a long-term decision and any structural changes in the network may lead to significant pay-offs. Therefore, the decision on how to form collaborative network requires sufficient managerial attention and organizational resources.

In this paper, the problem of how to develop an effective "collaborative network" (CN) is considered in the context of IT industry. An Iranian large-scale IT firm wants to establish a goal-oriented network as a kind of "collaborative networked organization" (CNO) to develop an "enterprise resource planning" (ERP) for universities, called "integrated university management system" (IUMS). The assumed CN consists of a focal firm and members and is adapted to $\mathrm{CNs}^{\prime}$ definition as described in the next section. The focal firm, as the manager of the network, selects some firms as the network's members and each member undertakes some parts of the project and possesses a portion of the final product's share. Obviously, the final products belong to all members of the network and the network is responsible for updating and supporting the product. In other words, the network has two forms in two levels of business; at first, the network is responsible for product development and after that the network changes its role to a service provisioning network in which it is responsible for supporting and upgrading the software and selling it in "software as a service" or any other form. In this paper, the focus is on the first level in which the product in under development by the network.

To address the problem, an integrated framework is proposed that involves both qualitative and quantitative methodologies to solve this problem. In the framework, two contemporary theories of interorganizational relationship, resource-based view and transaction cost theory, are combined; and a more comprehensive and applicable theory is provided. The justifications and advantages are discussed in the paper. Furthermore, a structured framework is proposed which includes a hybrid AHP and multiobjective programming and tries to provide a holistic view of the problem. At the end, the framework is implemented in the real case study and applicability of the framework is discussed.

In the subsequent sections, the proposed framework is described in detail. In Section 2, the theoretical background is discussed and the key concepts about collaborative networks, network formation, and rationale of interorganizational relationships are provided. In Section 3, the proposed framework is explained in detail. In Section 4, the implementation reports and the corresponding results are presented. In Section 5, the managerial implications, limitations, and the relevant future work are discussed.

\section{Theoretical Background}

In this section, theoretical backgrounds and the essential materials are provided. Related literature about collaborative networks, network formation, and rationale of interorganizational relationships are reviewed. These concepts form the underlying basis of the integrated framework proposed in this paper.

2.1. Collaborative Networked Organization (CNO). As mentioned by Camarinha-Matos and Afsarmanesh [14], the literature of interorganizational network is "a large but disjoint body of literature"; thus, we try to review different parts and provide a general big picture. The first part is "collaborative networks" which are defined by CamarinhaMatos and Afsarmanesh [4] as "an alliance constituted by a variety of entities (e.g., organizations and people) that are largely autonomous, geographically distributed, and heterogeneous in terms of their operating environment, culture, social capital, and goals." They classified the collaborative networks as (1) "collaborative networked organization" and (2) "ad hoc collaboration," where ad hoc collaboration can be accomplished in virtual communities and in notbusiness-oriented issues and most kinds of collaborative networks which act as an organization can be classified as the first class. They also classified the CNOs as two classes of (1) "long-term strategic networks" and (2) "goal-oriented networks." The first class tries to prepare the conditions and proper environment for fast and fluid configuration of the networks, when faced with opportunities. The second type-goal-oriented networks-derives from a specific goal like production or service providing activities [14].

Another stream is "strategic networks" which are defined as the firm's set of relationships, which are enduring and have strategic importance for firms entering them [1]. Brass et al. [12] define the strategic networks as a set of ties and nodes, where ties represent the relationships and nodes represent the actors including individuals, work units, and organizations. Gulati et al. [1] state that these strategic networks include interorganizational ties like strategic alliances, joint ventures, long-term buyer-supplier partnerships, and other similar ties. Jarillo [15] tried to develop the concept of strategic networks and discuss them in order to show their role as a mode of organization, also to analyze the economic conditions of strategic networks' existence. Stuart and Sorenson [16] discuss strategic networks and their role in entrepreneurial ventures. They present a well-organized literature review on 
the strategic network in the context of entrepreneurial issues and provide a research agenda in five major areas for a better understanding of the strategic networks. In this perspective, actors are embedded in greater networks of relationships and their conduct and performance should be analyzed with relevance to these networks which provide opportunities as well as constraints for the actors. Also, Kohtamäki et al. [17] discuss the strategic networks and focus on the effect of organizational identity on strategic network behavior and performance.

"Business networks" is another important stream which is known by some works like [3, 7, 18-21]. "Network organization" and "network of organizations" are two important concepts in this area. "Network of organizations" refers to "any group of organizations or actors that are interconnected with direct or indirect exchange relationships." Any market and the entire composition of the economy can be described in this manner as a network of ties and actors. But "network organizations" refers to the networks that define value system and the actor's roles and responsibilities [3]. Ritter et al. [13] propagate the concepts of deliberate and emergent networks or intentional and unintentional networks. Jarillo [15] believed that networks are intentional organization modes built to enhance firm's competitive positioning. Möller and Rajala [20] suggest that networks are emerging systems that individual firms are restricted by or dependent on. Other researchers provide different classifications; they distinguish between hub-driven networks and strategic multiactor networks [22, 23]. Also, Pulles et al. [24] provide an empirical study and discuss the essential characteristics of an actor for being an innovative contributor in the business network.

Based on the extant literature, the interorganizational collaborations can be analyzed at three different levels. The first level discusses dyadic relationships and effect of relationships in accessing and controlling resources. The development, management, and termination of relationships are discussed at this level. The interactions between two actors are the main issue of this level that is identified by many researchers [25-32]. The second level discusses the portfolio of relations that a focal firm maintained, sometimes called "portfolio of alliances" or "strategic nets." The questions are how to create these structures, how they affect the firm's performance, and how to manage this portfolio. See, for example, [20, 3341]. The third level is the broadest one and concentrates on networks. Usually, there is not an individual or focal firm but the whole structure of industry or market will be considered. The question is how network structures evolve and how to explain their dynamics. In addition, this level examines the effect of networks on firms and vice versa [7, 23, 42-46].

In this paper, the problem was defined in the class of a "goal-oriented network" in collaborative networks context where a network formed to accomplish a specific goal as an organization. In the "business network" context, the problem can be classified as an intentional, deliberate, and manageable network and also a hub-driven one which consists of a hub as coordinator and some members as value creators. Moreover, the problem was defined to tackle the portfolio level in interorganizational relationships and not in dyadic or industry network level.
2.2. Fundamental Theories on Interorganizational Relationships and Networks. There are a number of theories that describe the rationale behind the formation of interorganizational relationships. For example, [47] mentioned six theories about the formation of interorganizational relationships, including (1) transaction cost economics, (2) resource dependence, (3) strategic choice, (4) stakeholder theory of the firm, (5) organizational learning, and (6) institutional theory. Moreover, Parmigiani and Rivera-Santos [10] explore the key theories for explaining interorganizational relationships and mentioned theories like transaction cost economics, the resource-based view, knowledge-based view, dynamic capabilities, agency theory, resource dependence, stakeholder theory, institutional theory, and social networks. In this paper, two dominant theories, (1) transaction cost theory and (2) the resource-based view, are selected for consideration and the framework was based on them. This is because these two theories are the most general ones which other theories can be justified based on them and other theories can be seen as a branch of them or a combination of them [10]. Also, they are completely dominant in the literature in comparison with other theories and can perfectly cover the different aspects of the problem as described in the subsequent sections. These two theories are discussed in the following sections.

2.2.1. Transaction Cost Theory (TCT). Transaction cost theory has been widely used in literature as a theory of interorganizational collaboration [48-50]. The theory proposes that firms should determine their boundaries in order to minimize the sum of production cost and transaction cost. Indeed, this theory is developed to answer to the popular "make or buy?" question and describes that each value creation activity should be internalized or externalized in a way that minimize production plus transaction costs. In this theory, interorganizational relationships lead to reducing the uncertainties induced by market failure in addition to reducing associated costs [47]. The transaction cost refers to cost associated with exchange activities like writing and enforcing contracts and production cost associated with internal activities like producing, organizing, and managing.

As mentioned, TCT tries to address the make or buy decision. The firm should decide to produce using its own resource or purchase from the market. In addition, a firm could produce jointly through an alliance or interorganizational relationships. According to TCT, it is better to internalize when there are high transaction costs and low production costs. Transaction costs increased when the firm is encountered with a high rate of opportunistic behavior and high asset specificity. Merger and acquisitions could be seen as ways to internalization. It is better to externalize and use market transactions when production costs are high and transaction costs are low. Moreover, the firm could choose to ally when there are medium transaction and production costs and transaction costs are not high enough to justify internalization. Indeed, alliances could be seen as semiinternalization, and firms use it when internalization cost is more than market transaction but some limitations prevent full internalization [51]. 
There are some authors who criticize this theory in its ability to describe the formation of interorganizational relationships and generalization of this theory. There is a view that this theory is limited to economical and cost related issues, but some relations formed for some other reasons like learning, and these reasons could not be included in TCT [47]. However, [52] provide a critique that, according to TCT, all firms with similar transaction and production costs should make similar decisions about internalization and externalization, while this statement is untenable, and it could easily be seen that internalization/externalization decision dramatically differs along with a distinctive industry and in similar firms. Indeed, it should be argued that some complex factors (apart from economic and cost-based factors) should be considered in alliances, and using cost-based factors limits the quality of decision-making [53]. Although the simple logic of TCT provides useful and intuitive insights and causes widespread use of it, this simplicity causes some weakness that limits its effectiveness. Therefore, we suggest combining this theory with some other concept to improve its suability. In this paper, it is argued that TCT could be seen as complementary with resource-based view (RBV) and a combination of these two theories could be more advantageous.

2.2.2. Resource-Based View (RBV). Resource-based view of firm has been originated from the work of [54] and expanded in works by Wernerfelt [55] and Barney [56]. Resource-based view is seen as an inward-looking approach and in contrast with porter's competitive force. Teece et al. [57] mentioned four approaches in business strategy: (1) competitive force, (2) strategic conflict, (3) resourced-based perspective, and (4) dynamic capabilities. They introduce two former approaches as outward looking that emphasize on market power exploitation and the two latter as inward looking that emphasize on efficiency. They state that, according to RBV, firms are heterogeneous with their resources, and there is some degree of stickiness between firms and these resources and firms are forced to live with what they have and what they lack. This is because some resources and assets like reputation and tacit knowledge could not be easily tradable. Also, business development is complex and could not be easily achieved through the market.

The RBV emerged as an alternative approach for understanding the firm's competitive advantages. In this view, firms can be seen as a complex bundle of tangible and intangible resources. As mentioned before, $\mathrm{RBV}$ is in the contrast to the porter's competitive forces. Still, RBV emphasizes on the firm's resources and provides an inward-looking approach. RBV interprets the origin of competitive advantage in possessing valuable resources. Indeed, firms are heterogeneous with their resources and resources often are imitable, immobile, and firm-specific, and these resources could generate competitive advantage that could lead to economic rents or returns $[58,59]$. What a firm can perform effectively is a function of what it has possessed and so a firm's competitive advantages are defined by its resources [51]. One of the most important concepts of RBV is named as VRIO/N framework. According to this framework, not all types of resources could lead to sustained competitive advantages, but firm's resources that have four attributes could lead to sustained competitive advantages: (1) resources must be valuable (V), (2) rare among the firm's competitors (R), (3) imperfectly imitable (I), (4) have potential to be used by organizational processes $(\mathrm{O})$, or in another variant be nonsubstitutable $(\mathrm{N})$. These four attributes expose the heterogeneity, immobility, and usefulness of the firm's resources. According to this framework, if resources are not valuable, then they decrease firm's revenue and could be classified as weaknesses and named as competitive disadvantages. If resources are valuable but not rare, exploiting them will generate a competitive parity. If resources are valuable and rare, but easily imitable, they will generate temporary competitive advantages. And finally, if resources are valuable, rare, and costly to imitate and could be exploited by the organization then these resources could lead to sustained competitive advantages $[56,60]$.

The TCT and RBV are dominant theories in justifying the rationale of interorganizational relationships. As previously mentioned, resources that are valuable, rare, costly to imitate, and nonsubstitutable can make competitive advantages and these types of resources could not be purchased from the market; thus, firms try to achieve them through interorganizational relationships, sometimes called intermediate market. Firms rationale for creating relationships are to exchange, share, and combine valuable resources with other firms. In summary, there are two general motives for firms to ally: (1) to achieve the other's resources and (2) to maintain and develop its own resource in combination with other's resource [51]. Some authors $[51,61]$ compare the TCT and RBV logic in interpreting firm's relationships. TCT tries to economize transaction and production costs and presents proper governance structure, while RBV tries to maximize profits in the long-term by exploiting and developing resources. Moreover, TCT proposes to ally when transaction costs are not so high and take an intermediate place, while RBV proposes to ally when critical resources are needed by the focal firm owned by other parties and these resources are inseparable from other resources of the owner.

In summary, despite being criticized, these two theories have been widely used over a period of time by many authors. TCT concentrates on minimizing costs whereas RBV concentrates on maximizing value obtained from the relations. These two approaches can be integrated and used in a complementary way, to increase the potential relative strength of the two theories [53, 61, 62]. TCT only attends to cost-based issues and RBV could compensate this weakness. In addition, TCT could consider the opportunistic behavior of firms which occurs in specific circumstances and it proposes useful statements that could not be found in RBV. Also, TCT assumes that all firms can produce or offer services equally effective and this weakness could be compensated by incorporating RBV, because in RBV each firm's performance is determined by its complex bundle of resources and RBV explicitly differentiates firms in their performance [61]. Furthermore, RBV and TCT theories have been employed in justification of issues in the various fields of study; for example, [63] discussed the portfolio selection problems from TCT viewpoint and [64] discussed alliance 
formation justification by RBV theory. In this paper, these two theories are integrated to maximize their potential and implemented employing analytical tools. We propose that the combination of these two could interpret the reality better and lead to the better results.

2.3. Network Formation. There are a handful of papers which discuss the "network formation" problem and they are from different scientific streams. Thus, in this section, the papers related to "network formation" are identified and briefly reviewed. Some authors explain the formation of relations at the dyadic level. David et al. [65] explain the stages of dyadic relationship building in five phases, namely, (1) the prerelationships stage, (2) the early stage, (3) the development stage, (4) the long-term stage, and (5) the final stage. After that, Dwyer et al. [66] provide a framework for developing buyer-seller relationships. They proposed a formation process that incorporates five phases: (1) awareness, (2) exploration, (3) expansion, (4) commitment, and (5) dissolution. Also, Larson [67] discussed the three stages of relationship making, (1) preconditions for exchange, (2) conditions for building, and (3) integration and control. Wilson [68] tried to combine the empirical knowledge about the successful relationship in an integrated model and provide a conceptual process for developing buyer-seller relationships. The proposed model consists of five stages including (1) partners search and selection, (2) defining the purpose, (3) setting relationship boundaries, (4) creating relationship value, and (5) relationship maintenance. In recent papers, Abosag and Naudé [69] focus on the development of a special form of B2B relationship and discuss the role of interpersonal liking and trust in the relationship development. They provide a conceptual model and use the SEM methodology. Gumerov et al. [70] discuss the features of forming a dyadic relationship in interaction network environment and entrepreneurial structure. Lacoste and Johnsen [71] discuss the dynamics and balance of power in relationships between supplier and customer and describe their actions to improve countervailing power. Mandják et al. [72] focus on the question of "how a business relationship emerge?" and discuss the first stage: "birth of a new relationship." They provide a conceptual framework and discuss the different trust building scenarios. Then, they worked on trigger issues in initial stage which boost an emerging relationship and provide a logical framework [73]. Finally, Hennelly and Wong [74] explore the formation of new relationship in nascent industries with high uncertain environment by longitudinal case studies. They discussed three concepts: compatibility, complementarity, and relationship life cycle in the relationships formation.

At the network level, Ebers [75] explain the network formation and provide useful insights and they discuss dynamics and costs of interorganizational networks. David and Keely [76] discuss collaborative network formation in multiple funding agencies. Hinterhuber [77] explains the concept of virtual value chain as an emergent phenomenon and provides a process model for forming such a network. The proposed model consists of six phases: (1) analysis of firm value chain, (2) analysis of the flow of goods and total value created, (3) identification of ways to increase the amount of value created by the extended value chain, (4) configuration of the network around value creation opportunities, (5) identification of ways to capture value created (alliances, joint ventures, and acquisitions), and (6) managing the crossindustry value chains. Ozcan and Eisenhardt [34] develop a process view for building portfolio of relations in the context of entrepreneurial firms. Their process framework consists of three strategies for building portfolio of interorganizational relations: (1) to advocate unique industry architecture that proactively shapes the industry, (2) to take long jumps to exploit opportunities to coordinate unconnected firms, and (3) to defend against emerging industry uncertainties when they occur. Partanen and Möller [23] develop a process model for the strategic network formation problem based on value creation system approach. Their process consists of 8 stages: (1) determination of value creation activities, (2) determination of the value creation system, (3) determination of objectives and analysis of target activities, (4) comparing resources and activities with target activities, (5) analysis of delegated activities, (6) conducting preliminary partner assessment, (7) negotiating with alternative partners, and (8) launching interfirm collaborations. They implemented their proposed process model in the ICT sector and discussed the implementation points and managerial implications. Gaspar et al. [78] organize a descriptive-qualitative study and determine the factors which influence, promote, or restrict the formation of a cooperative network. In another work, Hale and White [79] develop a framework for the establishment of a collaborative networks. They explore four case studies in aerospace and renewable industry and propose a framework consists of eight elements: (1) purpose definition, (2) funding mechanism, (3) identification and selection of partners, (4) defining collaborative objectives, (5) network structure, (6) governance processes, (7) defining risks, and (8) requirement for success. They claim that the process of member identification and selection in the networks is one the key gaps. Jussila et al. [80] conduct a qualitative case study and focus on strategic network formation between second-tier actors in the field of construction megaprojects. They determined six strategic networks in the case and discuss their types and roles and also uncertainties regarding network formation. Zhang and Pezeshkan [81] discuss the alliance formation of a foreign firm in the host country and explore the role of firm's position in the network. They integrate theories of resource dependence and social network to provide a better understanding of alliance formation phenomenon. Moreover, there are a lot of works which discuss the formation of virtual organizations and enterprises as a kind of collaborative networks, like [82-85].

To sum up this section, it should be said that the literature on interorganizational relationships, as described by Parmigiani and Rivera-Santos [10], is very expanded and complex. Thus, we try to classify it and provide a big picture on the field of interorganizational relationships formation. Therefore, Table 1 categorizes the reviewed literature on the formation phase of interorganizational relationships. 
TABLE 1: Summary of reviewed papers in formation phase of interorganizational relationships.

\begin{tabular}{|c|c|c|c|c|c|c|}
\hline \multirow{2}{*}{ Paper } & \multicolumn{3}{|c|}{ Level } & \multirow{2}{*}{ Theoretic } & \multirow{2}{*}{ Descriptive/prescriptive } & \multirow{2}{*}{ Type of achievement } \\
\hline & Dyadic & Portfolio of relations & Networks & & & \\
\hline [66] & $r$ & & & & Descriptive & Framework \\
\hline [67] & $\checkmark$ & & & & Descriptive & Framework \\
\hline [68] & $\checkmark$ & & & & Descriptive & Framework \\
\hline [75] & & & $\checkmark$ & & Descriptive & Conceptual model \\
\hline$[48]$ & & $\checkmark$ & & $\checkmark$ & Descriptive & Theoretical propositions \\
\hline$[65]$ & $\checkmark$ & & & & Descriptive & Framework \\
\hline [49] & & $\checkmark$ & & $\checkmark$ & Descriptive & Theoretical propositions \\
\hline [51] & & $\checkmark$ & & $\checkmark$ & Descriptive & Theoretical propositions \\
\hline [61] & & $\checkmark$ & & $\checkmark$ & Descriptive & Theoretical propositions \\
\hline [47] & & $\checkmark$ & & $\checkmark$ & Descriptive & Theoretical propositions \\
\hline$[58]$ & & $\checkmark$ & & $\checkmark$ & Descriptive & Conceptual model \\
\hline [77] & & $\checkmark$ & & & Prescriptive & Framework \\
\hline$[76]$ & & & $\checkmark$ & & Descriptive & Conceptual model \\
\hline [34] & & $\checkmark$ & & & Prescriptive & Framework \\
\hline [23] & & $\checkmark$ & & & Prescriptive & Framework \\
\hline [69] & $\checkmark$ & & & & Descriptive & Statistical propositions \\
\hline$[78]$ & & & $\checkmark$ & & Descriptive & Affecting factors \\
\hline [79] & & & $\checkmark$ & & Descriptive & Framework \\
\hline [70] & $\checkmark$ & & & & Descriptive & Mathematical analysis \\
\hline [71] & $\checkmark$ & & & & Descriptive & Conceptual model \\
\hline [72] & $\checkmark$ & & & & Descriptive & Conceptual framework \\
\hline [73] & $\checkmark$ & & & & Descriptive & Logical framework \\
\hline$[74]$ & $\checkmark$ & & & & Descriptive & Theoretic implications \\
\hline [80] & & & $\checkmark$ & & Descriptive & Conceptual model \\
\hline [81] & & $\checkmark$ & & $\checkmark$ & Descriptive & Theoretic implications \\
\hline
\end{tabular}

Based on Table 1 and reviewed literature, the gaps in the literature which are in the focus of this paper are listed below as follows:

(i) There is a significant lack of prescriptive solutions for the formation problem in the level of networks and portfolio of relationships. The prescriptive solutions, which generally include mathematical models, are common and tackle the formation problem in the dyadic level.

(ii) There is a weak relationship between fundamental theories and applied models, and applied models generally are constructed by case study's requirements and not by considering fundamental theories.

(ii) The complementarity of RBV and TCT theories are mentioned by some authors, as described earlier, but there is a lack of solutions for conceptualization and employment of it in a hybrid theory.

Owing to these points, the aim of this paper is to fill the mentioned gaps by providing a practical, prescriptive framework based on the fundamental theories. A hybrid of RBV and TCT theories was considered as fundamental theory and a practical framework and analytic solution were developed based on it.

\section{The Proposed Framework for Collaborative Network Formation}

As stated before, the framework aims at addressing network formation problem where a focal firm as a hub wants to establish a portfolio of relations for developing a specific business or product. In this problem, the focal firm needs to determine the scope to be internalized and those that should be assigned to the others, also choosing among available alternatives for externalized activities. The set of these actors, as a portfolio of relations, makes the network a synergic network that provides the predefined goals in a highly flexible, agile, and responsive to environmental changes way. It should be mentioned that the process of establishing a portfolio of alliances, as mentioned by Wilson [68], is a difficult and time-consuming process and sometimes needs to do iterative actions of gathering information, planning, acting, and reforming but may provide superior results.

The framework proposed in the following subsections consists of five stages. The framework involves both qualitative and quantitative aspects of the problem definition and solution. The framework includes a multiobjective mathematical model that formulates RBV and TCT theories. Indeed, the proposed framework integrates two important problems, namely, determination of externalization activities 
and choosing the best partner for them; this integration could lead to better answers and will result in an effective network.

\subsection{Stage 1: Determining the Value Creation Activities Map} (VCAM). Firstly, the hub firm assesses its value creation activities to develop a map that identifies high-level value creation activities and their relations. Indeed, VCAM shows the activities that should be accomplished through the network. The VCAM is an important perquisite of the framework, because it should identify the areas of responsibilities among network members. Some models like "value chain model" [86] and "value creation system" [87] can be useful for determining value creation activities. Adopting Porter's concept, the value creation system divides the activities into two main categories, realization and support activities. Realization activities are those that create goods or services, and support activities are those that do not directly participate in creating products, but help the other activities in terms of their efficiency. It is noticeable that value creation activities are not necessarily organizational units but those which provide value to end users. Customers' needs and desires are important factors for this map. The resulted map should properly reflect these needs and illustrate the activities that lead to them.

3.2. Stage 2: Determining the Most Important Activities That Should Be Internalized. In this stage, the most important activities that should be accomplished by the hub firm will be identified. The activities that are included in VCAM and the network will be formed based on them. The hub firm wants to assign activities in VCAM to the network members and perform key activities by itself in order to maintain its place as a hub. The firm focuses on the activities that are in conformation with its capabilities. For this purpose, the hub firm capabilities will be classified, and the most important activities from VCAM that are in conformity with these capabilities will be selected for internalization. Researchers have addressed the problem of identifying and classifying the firm's capabilities $[58,59,88]$. For this part, we adopt and extend the work of [89]. According to resourcebased view of the firm, they state that each firm has some resources; resources could potentially build capabilities and some capabilities with special features from firm's competencies. Any capabilities that have two important criteria, "uniqueness" and "collectiveness," could be classified as firm's competencies. As illustrated in Figure 1, each capability that has a high score in uniqueness and collectiveness could be seen as firm's competencies.

Based on the above-mentioned concepts, the hub firm capabilities will be classified and the most important activities that are in conformity with these capabilities will be selected for internalization. This classification is resolved by using the criteria of "uniqueness" and "collectiveness." Uniqueness is assessed by three measures, namely, rareness, Inimitability, and nonsubstitutability. Likewise, collectiveness is assessed by three measures, namely, Across-product, Acrossfunction, and Across-business. The capabilities are classified under three categories, namely, (1) core competences,

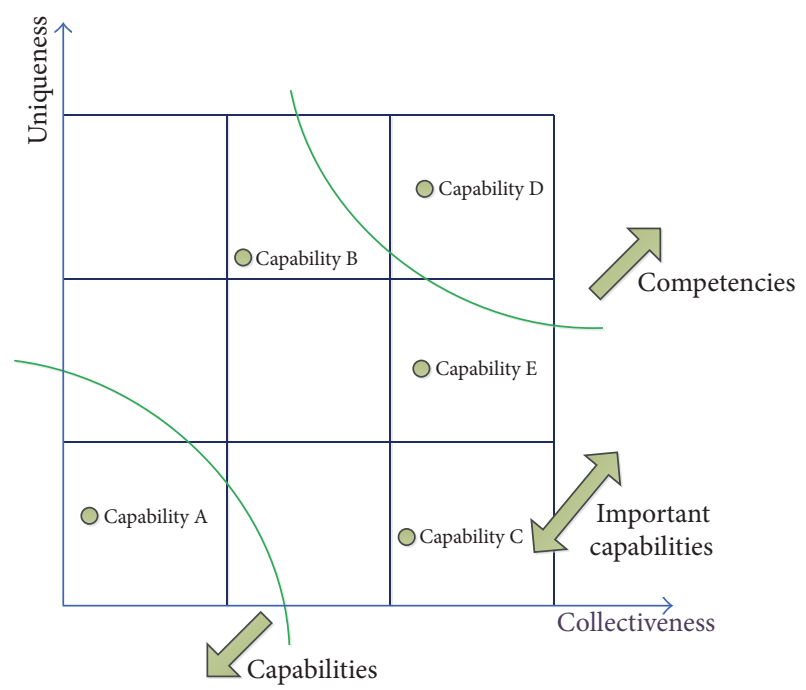

Figure 1: Capability classification scheme.

(2) competences, and (3) capabilities. Core competences are the most important capabilities and activities related to this category of capabilities selected for internalization.

\subsection{Stage 3: Determining Potential Partners for Activities and} Their Preliminary Assessment. In this stage, efforts concentrate on identifying potential partners for each remaining activity from the previous stage (that still need to be selected). Subsequently, a preliminary assessment of these is conducted at this stage. Each remaining activity from the previous stage could be performed by hub firm or by one of the potential partners identified in this stage, and, obviously, each potential partner could be considered for more than one activity. The alternatives which will be chosen are those that possess necessary resources and capabilities for accomplishing the activities. Potential partner selection will be done by evaluating industry network. Industry network assessment could provide useful information by analyzing relationships, communities, and network properties by tools like "social network analysis" (SNA) and tools introduced for network economy analysis like [90]. Also, alternatives could be chosen by considering previous alliances and collaborators that have valuable, rare, and noninimitable resources.

Following this, initial assessment of potential partners will be conducted. The first prerequisite at this stage is gathering enough information about each alternative. Some alternatives' attributes could be more important at this stage, like information about their previous experience in alliances, level of trust and commitment, and their willingness to share tacit knowledge. Also, some other information like strategic goals and objectives, market position, organizational culture, structure, and processes could be useful at this stage.

\subsection{Stage 4: Eliminating Unqualified Alternatives through} Assessment of Noncompensatory Criteria. In this stage, some unqualified alternatives would be eliminated from the decision-making procedure. For this purpose, a selective 


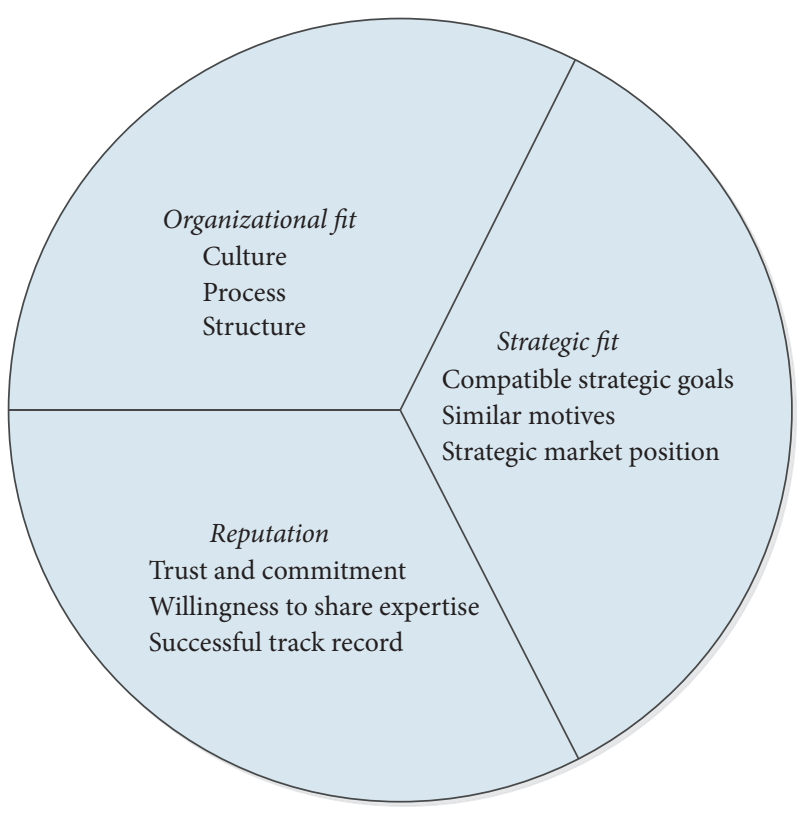

FIGURE 2: Noncompensatory criteria conceptualization.

literature review was conducted to determine the important criteria. Subsequently, the efforts are to be concentrated on constructing a model that can conceptualize the determination criteria. In this stage, the focus is on noncompensatory criteria, where alternatives must score more than a specific threshold level, allowing to discard any activates below the threshold. In other words, each potential partner that scores below the acceptable level would be eliminated. Indeed, the criteria mentioned in this stage are intrinsically different with the next stages, because in this stage the criteria will be used as noncompensatory and for elimination of alternatives and in the next stages the aim is to rank the alternatives with compensatory criteria. Thus, it is possible to find similarities between this stage's criteria with the next stages. These noncompensatory criteria were conceptualized and illustrated in Figure 2. The criteria used in this stage consist of three categories: (1) organizational fit, (2) strategic fit, and (3) reputation. "Organizational fit" is related to fitness between hub firm and its potential partners. This fitness should occur in three dimensions like cultural, process, and also structure similarity. "Strategic fit" is related to conformity of strategic issues between hub firm and its potential partners. These issues are adaptation in goals, objectives and values, adaptation in motives for entering into an alliance, and also the similarity of their market position. The third category is named "reputation" and is related to some social attribute of the potential partner firm, like anticipating trust and commitment, his willingness to share valuable expertise and tacit/explicit knowledge, and also record of his behavior in previous alliances.

The aim at this stage is that the managers and decisionmakers (DMs) are assured that selected alternatives meet the minimum requirements. In the final stage, the best partner alternatives will be chosen based on some compensatory criteria.

3.5. Stage 5: Final Selection of Network Members. In this stage, network members will be selected and activities of VCAM assigned to them. In other words, the hub firm's portfolio of alliances will be determined. For this purpose, a mathematical model is proposed that leads to hub firm's network. The proposed model complements the previous stages. The model is a multiobjective decision-making model one that exploits two objectives, (1) maximizing the total value gained from the portfolio of relationships (RBV objective) and (2) minimizing total transaction and production cost (TCT objective). Table 1 describes the linear programming model parameters. There are some works in the literature which have similar aim, like [91].

Parameters of a Linear Programming Model for Network Partner Selection

Indices

$i$ : activities $i \in I=\{1,2, \ldots, n\}$.

$j$ : candidates for each activity $j \in J=\left\{1,2, \ldots, m_{i}\right\}$.

$H$ : set of related activities $\{(s \cdot k) \in H$. activity $s$ is related to activity $k$ \}.

\section{Input Parameters}

$\mathrm{Un}_{i j}$ : relative uniqueness achieved through relationship with candidate $j$ in activity $i$.

$\mathrm{Co}_{i j}$ : relative collectiveness achieved through relationship with candidate $j$ in activity $i$.

$\operatorname{Pr}_{i j}$ : relative production cost of candidate $j$ in activity $i$.

$\operatorname{Tr}_{i j}$ : relative transaction cost of candidate $j$ in activity $i$.

$C_{i j}$ : total budget needed by candidate $j$ to accomplish activity $i$.

$T_{i j}$ : time needed for candidate $j$ to accomplish activity $i$.

PDD: planned due date of the project.

$\beta$ : total accessible budget.

\section{Problem Variables}

$\operatorname{DUE}(i)$ : the planned finish time of activity $i$.

$X_{i j}=1$. If activity $i$ allocated to candidate $j$; otherwise $X_{i j}=0$.

One key point in this formulation is that the hub firm could be a potential alternative for performing activities, and, in such case, the first counter of set $J$ (set of potential candidates for each activity) will dedicate to hub firm. The proposed model consists of two objectives and three sets of constraints. The mathematical formulation consists of objectives and constraints defined as follows: 


$$
\begin{array}{cl}
\max \quad & Z_{1}=f_{1}\left(X_{i j}\right)=\sum_{i=1}^{n} \sum_{j=1}^{m_{i}}\left(W_{1} \mathrm{Un}_{i j} \cdot X_{i j}+W_{2} \mathrm{Co}_{i j} X_{i j}\right) \quad \text { objective (1) } \\
\min \quad Z_{2}=f_{2}\left(X_{i j}\right)=\sum_{i=1}^{n} \sum_{j=1}^{m_{i}}\left(W_{1}^{\prime} \mathrm{Pr}_{i j} \cdot X_{i j}+W_{2}^{\prime} \operatorname{Tr}_{i j} X_{i j}\right) \quad \text { objective (2) } \\
\text { Subject to: } \quad \sum_{j=1}^{m_{i}} X_{i j}=1 . \quad \forall i \in I \\
& \operatorname{DUE}(i) \leq \mathrm{DUE}(k)-\sum_{j=1}^{m_{i}} T_{k j} \cdot X_{k j} \quad \forall(i \cdot k) \in H \\
& \mathrm{DUE}(n)=\mathrm{PDD} ; \\
& \sum_{i=1}^{n} \sum_{j=1}^{m_{i}} C_{i j} \cdot X_{i j} \leq \beta \\
& \text { contingent constraints related to portfolio effect of alternatives }
\end{array}
$$

The above model is described detailing required objectives and constraints.

Objective (1) (Maximizing Total Value Gained from the Portfolio of Relationships (1)). This objective aims to maximize total gained value from the portfolio of relationships. In the formulation of this objective, two parameters of uniqueness and collectiveness are considered as introduced by Hafeez et al. [89]. They state that the resources with high degree of these two characteristics could qualify as firm's competencies and could lead to competitive advantages. Uniqueness shows the degree at which the firm's resources are solitary in type or characteristics in the market place, and collectiveness depicts that these capabilities are wide spread in the organization and could be found in any product and services and constitute a new pattern of competition for the firm. Uniqueness and collectiveness were measured by AHP method as shown in Figure 3. The AHP criteria were taken directly from the work by Hafeez et al. [89] and the weights will be determined by pairwise comparison of alternatives and criteria in conventional AHP manner, and final alternative weights will be used in objective function.

Objective (2) (Minimizing Total Production and Transaction Costs (2)). This objective function tries to minimize total production and transaction costs. According to TCT theory, total transaction costs and production costs must be minimized by answering the internalization/externalization question. This objective function utilizes two parameters of production cost and transaction cost. Production and transaction costs were measured by AHP method as shown in Figure 4 and final weights will be used in the objective (2) as a parameter. The criteria of production and transaction cost are inspired from the works by Dyer [48], Madhok and Tallman
[49], and Tsang [61] and the weights will be determined by pairwise comparison, in conventional AHP way, and final alternative weights will be used in objective function. It is noteworthy to say that objective (2) (TCT objective) describes the short-term benefits of the hub firm and objective (1) (RBV objective) relies on the long-term benefits. Thus, the decision-maker could trade-off between these two objectives by a balancing coefficient.

Equation (3) (Activity Allocation Constraint). The constraint guarantees that each activity will be allocated to at least one candidate. It should be noticed that the hub firm could be one of the candidates and the activity may be allocated to the hub firm.

Equations (4), (5), and (6) (Total Time and Cost Constraint). As network will be formed for a specific software development project and the network is responsible for updating, maintenance, marketing, sales, and so on, so each activity should be accomplished in a time window and the total project must be finished before the predetermined due date. In this situation, perquisite relations between activities cause a formulation as suggested in (4). It is noticeable that a dummy start and end activity should be added to activity map so that the start activity depicts the start time of the project and the end activity depicts the final project due date. In addition, there is a cost constraint. The focal firm as network manager should control the total cost of the product.

Constraints (7) (Portfolio Effect). Some constraints arise according to the portfolio effect that different potential partners imposed to the hub firm. For example, it is possible that the hub firm does not want to have two conflicting partners in its portfolio simultaneously. 

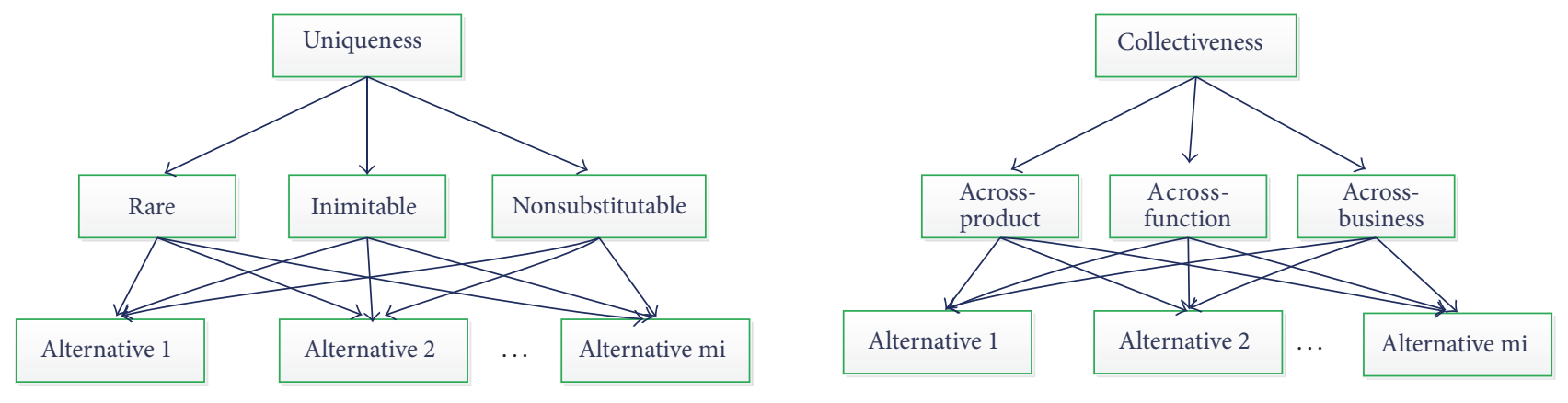

Figure 3: AHP hierarchies for assessment of uniqueness and collectiveness.
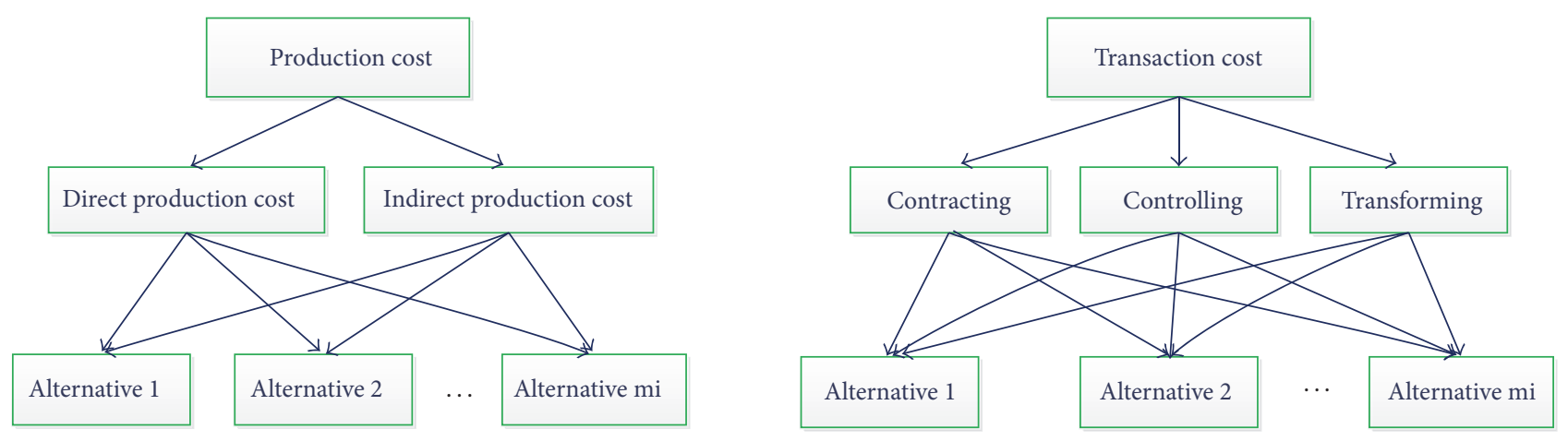

FIGURE 4: AHP hierarchies for assessment of production and transaction cost.

\section{Implementation}

The proposed framework was implemented in a project established for development of a total solution for universities, named as integrated university management system (IUMS). The IUMS project was planned in three scenarios, namely, plans $\mathrm{A}, \mathrm{B}$, and $\mathrm{C}$. In plan $\mathrm{A}$, the project will be performed completely by the project team. In plan $B$, the project team will be engaged in the development of the system in the modules that are completely related to university functions. Finally, in plan C, almost all of system modules will be performed by partner firms and the project team will be focused on the integration of modules and control of transactions between modules. Plan A has the highest cost and duration, whereas plan $\mathrm{C}$ has the lowest cost. Thus the framework was implemented in order to determine the optimal solution. The components and users of IUMS system were shown in Figure 5. The system was designed based on service-oriented architecture (SOA), where the IPIMS works as integration module and relates other modules to each other based on SOA. Also, the system should serve some users like students, lecturers, professors, staff, partners, and governments as shown in the figure. The value creation activity map was shown in Figure 6. This map illustrates the activities that should be done by the network, and each activity creates a specific value for the end user.

In the next stage, the aim is to determine the most important activities for the hub firm to internalize. A methodology was proposed for this stage in the previous section.
The methodology was based on analysis of hub firm's capabilities and two criteria of "uniqueness" and "collectiveness." Thus, the hub firm's capabilities were analyzed and classified based on the two aforementioned criteria and by AHP technique, as described in stage 2 of the framework, and the result was shown in Figure 7.

Then, the potential partners for each activity were identified. Thus, after interviews with experts and a brief analysis of the results, an initial number of alternatives were determined. These alternatives were investigated precisely and unqualified ones were omitted from the procedure.

In stage 4, qualitative analysis of alternatives was conducted, and unqualified alternatives were excluded from the rest of procedure. The main criteria, as described earlier, are reputation, organizational fit, and strategic fit. In the IUMS case, reputation was the most important criterion.

In stage 5 , the final selection of network members will be done. The most important parameters that are utilized in the mathematical model of this stage are Un, Co, Pr, and Tr. Also, there are four weight parameter in the objectives as shown in formulas (1) and (2). The weights are set as 0.65 for uniqueness and 0.35 for collectiveness and 0.65 for production cost and 0.35 for transaction cost.

Subsequently, the mathematical model was implemented in GAMS and the obtained results were discussed. As the model was a hybrid of AHP and multiobjective mathematical programming, the appropriate techniques were employed, namely, (1) weighting method, (2) method of global criterion, (3) lexicographic method, (4) the method of satisfactory goals 


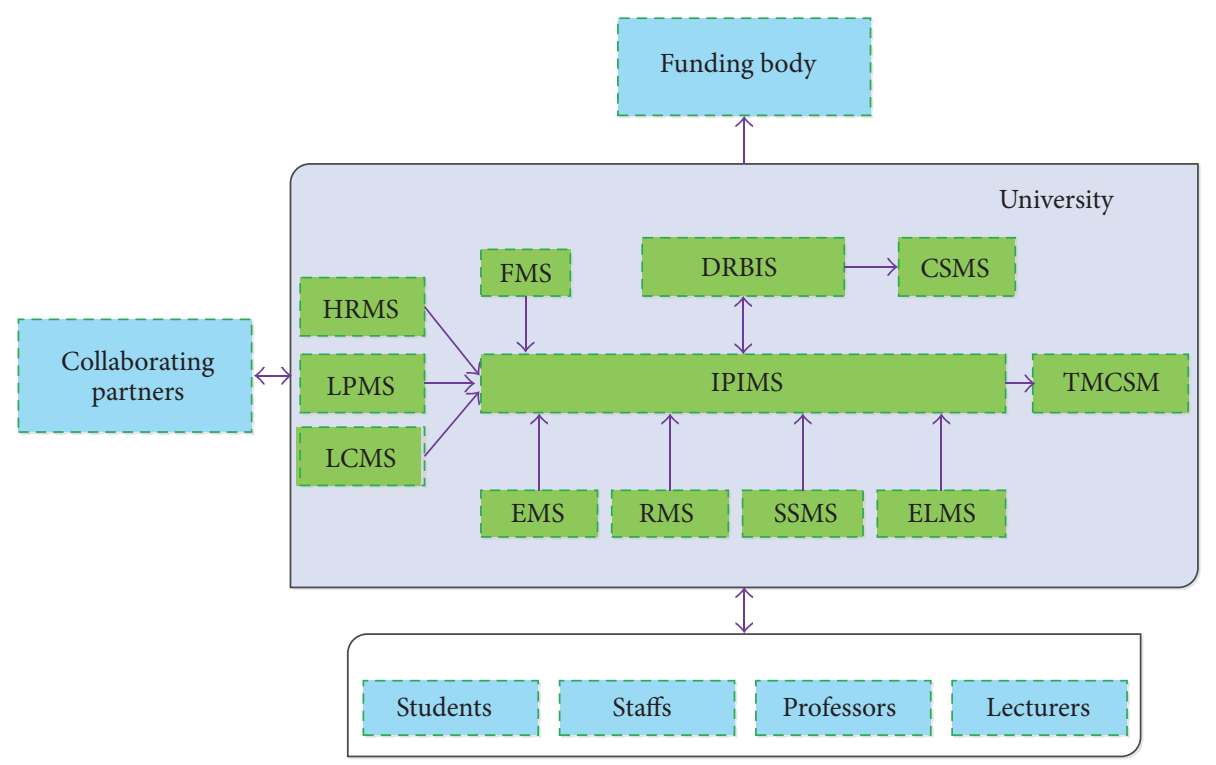

FIGURE 5: The IUMS components.

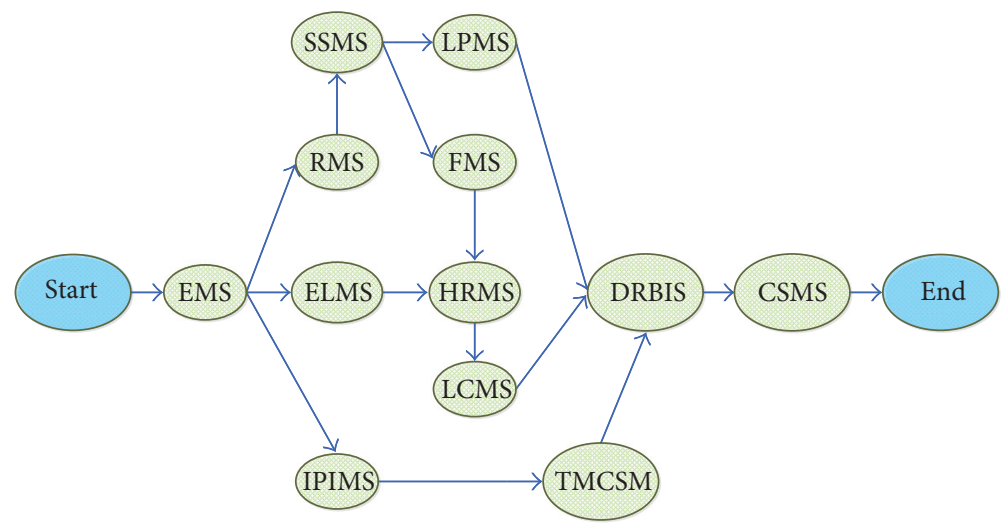

FIGURE 6: IUMS value creation activities map.

TABLE 2: Classification of the optimization methods employed.

\begin{tabular}{ll}
\hline Classification & Method name \\
\hline Basic methods & (1) Weighting method \\
No preference & (2) Method of global criterion \\
Priori preference & (3) Lexicographic method \\
Posteriori preference or & (4) The method of satisfactory goals \\
interactive methods & (5) SIMOLP \\
\hline
\end{tabular}

$[92,93]$, and (5) simplified interactive multiple objective linear programming (SIMOLP) [94]. The employed techniques were illustrated in Table 2 . The techniques were selected based on their adaptation with problem structure. Also, it was tried to select at least one technique in each class of techniques.

The weighting method, as a simplistic and straightforward method, was selected because it can provide a simple, reasonable, and understandable way of solving the MOADM problem. The method of global criterion was selected from the no preference class, where there was no need to judge the preferences. The lexicographic was selected from the priori preference class in which the decision-makers should determine their preferences before the running of the algorithm. Also, two methods, SIMOLP and the method of satisfactory goals, were selected from the class of posteriori or interactive preferences where decision-makers provide their judgement interactively or after the running of the problem. The obtained results from above-mentioned methods were illustrated in Table 3. In weighting method, the solution achieved by solving this problem

$$
\begin{aligned}
\max \quad Z & =w_{1} f_{1}+w_{2} f_{2} \equiv \max Z^{\prime}=f_{1}+\frac{w_{2}}{w_{1}} f_{2} \\
\alpha & =\frac{w_{2}}{w_{1}} .
\end{aligned}
$$

As illustrated in the formulation above, the objectives are sum up with different weights, and it is possible to divide the formulation by one of the weights and solve the problem 


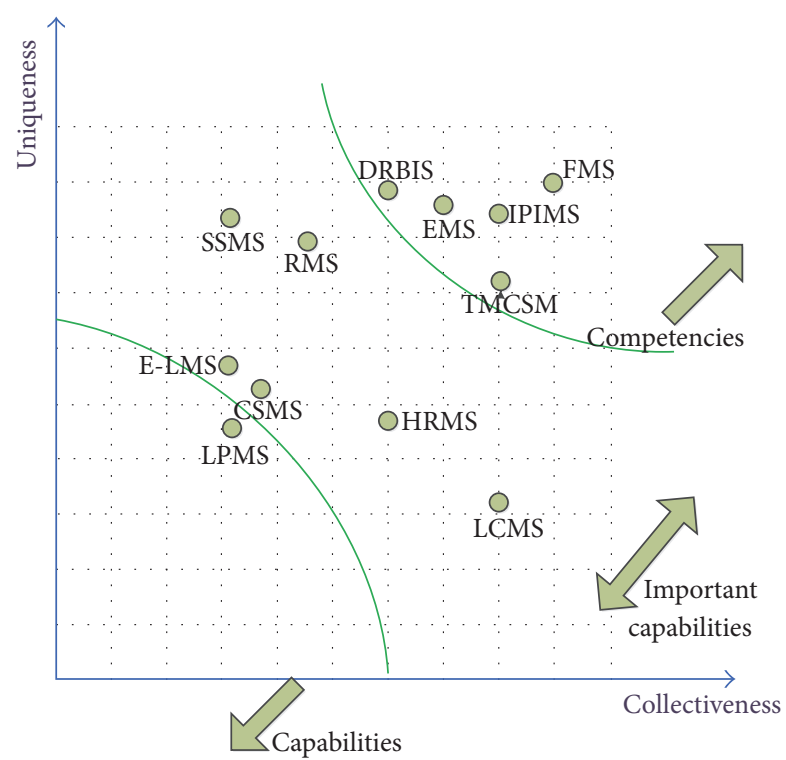

Figure 7: Capabilities classification.

TABLE 3: The obtained results from the different methods.

\begin{tabular}{|c|c|c|c|}
\hline \multirow{2}{*}{ Methods } & \multirow{2}{*}{ Parameters } & \multicolumn{2}{|c|}{ Results } \\
\hline & & RBV & TCT \\
\hline \multirow{4}{*}{ Weighting method } & $\alpha<0.08$ & 2.320 & 1.760 \\
\hline & $0.08 \leq \alpha<0.2$ & 2.274 & 1.773 \\
\hline & $0.2 \leq \alpha<0.6$ & 2.261 & 1.852 \\
\hline & $\alpha \geq 0.6$ & 1.166 & 3.258 \\
\hline Global criterion & $P=1$ & 2.261 & 1.852 \\
\hline \multirow{14}{*}{ Lexicographic } & $\begin{array}{c}\text { Preferred obj. = RBV, } \\
\text { RBV } \geq 2.3\end{array}$ & 2.32 & 1.76 \\
\hline & $\mathrm{RBV} \geq 2.2$ & 2.261 & 1.852 \\
\hline & $\mathrm{RBV} \geq 2.1$ & 2.138 & 1.988 \\
\hline & $\mathrm{RBV} \geq 2.0$ & 2.032 & 2.155 \\
\hline & $\mathrm{RBV} \geq 1.9$ & 1.972 & 2.247 \\
\hline & $\mathrm{RBV} \geq 1.8$ & 1.804 & 2.396 \\
\hline & $\begin{array}{c}\text { Preferred obj. = TCT; } \\
\text { TCT } \geq 3.2\end{array}$ & 1.166 & 3.258 \\
\hline & $\mathrm{TCT} \geq 3.0$ & 1.166 & 3.258 \\
\hline & $\mathrm{TCT} \geq 2.8$ & 1.454 & 2.863 \\
\hline & $\mathrm{TCT} \geq 2.6$ & 1.684 & 2.603 \\
\hline & $\mathrm{TCT} \geq 2.4$ & 1.743 & 2.511 \\
\hline & $\mathrm{TCT} \geq 2.2$ & 1.972 & 2.247 \\
\hline & $\mathrm{TCT} \geq 2.0$ & 1.986 & 2.168 \\
\hline & $\mathrm{TCT} \geq 1.8$ & 2.261 & 1.852 \\
\hline Satisfactory goals & $\mathrm{TCT} \geq 1.8 ; \mathrm{RBV} \geq 2.0$ & 2.261 & 1.852 \\
\hline SIMOLP & - & 2.261 & 1.852 \\
\hline
\end{tabular}

with one parameter named alpha, which can vary from zero to infinity. The problem was solved with different alpha by steps equal to 0.1; after numerous run, the four solutions were obtained. In the second method, the global criterion method, the efforts are on the minimization of the gap between objectives and their optimum value as shown in formula (9) as follows:

$$
\min Z=\sum_{i=1}^{k}\left(\frac{f_{i}\left(x^{*}\right)-f_{i}(x)}{f_{i}\left(x^{*}\right)}\right)^{p} .
$$

The problem was solved with this method and $p$ set to 1 . Hence, the problem was transformed into a nonlinear problem. The problem was solved with "MINLP" solver of GAMS and the results were reported. In the lexicographic method, the objectives were ranked based on their importance. The solution was obtained by optimizing the most important objectives and the procedure will continue by objectives orders. The first-order objective sets as equal to its optimum value and was placed in constraints, as shown in formula (10).

$$
\begin{array}{cl}
\max & f_{2}(x) \\
\text { s.t. } & g(x) \leq 0 \\
& f_{1}(x)=f_{1}^{*} .
\end{array}
$$

In the formula, objective 1 is preferred to objective 2. After solving the problem with this objective, the preferred objective with the optimal value was set as a constraint and the problem was solved with the second-order objective. In an extension of the lexicographic method, it is possible to let the first-order objective tolerate with level as shown in formula (11).

$$
\begin{array}{ll}
\max & f_{2}(x) \\
\text { s.t. } & g(x) \leq 0 \\
& f_{1}(x) \geq f_{1}^{*}-\delta_{1} .
\end{array}
$$

The lexicographic method was implemented with different tolerate level and with different preferences about the objectives, and the results reflected in Table 3 . Since it was difficult to select one objective as the dominant, the problem was solved with the two alternative manners. In the satisfactory goal method, the decision-maker determines a set of acceptable goals for each constraint, after that the problem was solved with the objective which has the least satisfactory level and the rest of objectives are set as constraints. The problem was solved in different situations until reaching the solution that fulfills satisfactory levels of all objectives. Since there are only two objectives, the decision-makers could find the most satisfactory solution easily. At the end, the SIMOLP technique was run. In this technique, the problem was solved with weights that were achieved by a specific procedure. In the first, the problem was solved with each objective separately; then the weights were attained by solving the system of equation as depicted in formula (12).

$$
\sum_{j=1}^{j} w_{j} f_{j}^{l}-w_{k+1}=0 \quad \forall l \in H .
$$

After that the problem was solved with achieved weights; if the obtained solution was satisfactory, the procedure was 
TABLE 4: The favorable (or optimum) solution.

\begin{tabular}{cccccc}
\hline RBV & TCT & Variables & Alt. 1 & Alt. 2 & Alt. 3 \\
\hline 2.261 & 1.852 & RMS & & & 1 \\
& & SSMS & & & 1 \\
& & LPMS & & 1 & \\
& & HRMS & 1 & & \\
& & LCMS & & 1 & \\
& & CSMS & 1 & & \\
\hline
\end{tabular}

terminated; otherwise, the new solution was replaced with one of the previous and the procedure was repeated until a satisfactory solution would be obtained. In this problem, there are two objectives and a system of two equations. It is noticeable that the system of equations does not depend on $w_{k+1}$ and this parameter could be determined arbitrarily. In this problem, after two runs, the procedure leads to duplicated solution and was terminated automatically. But, the first solution after solving the system of equations was the most favorable and selected by the decision-makers.

The final solution was selected by comparing different solutions. Finally, the intersection of all methods' solutions was selected as reported in Table 4. It is noticeable that the selected solution was repeated in all methods as shown in Table 5.

\section{Methods Comparison and Discussions}

A firm's collaborative network, that consists of a focal firm and its relatives, has a significant role in the success of the members and also is an outstanding source of competitive advantage for the firms. In summary, the formation of a collaborative network is a long-term decision and therefore wants a careful selection process. Thus, the decision should be made with enough allocated time and budget to lead to good results.

The proposed framework was implemented in IUMS project and the results show that by consideration of such a network, the costs and project time can be reduced significantly. In addition, by this plan, the managerial load was decreased and the flexibility, in addressing the environmental and technological changes, was increased. The aim of the present work is to extend the current knowledge of collaborative network building. Previous works based on problem scope and employed tools could be classified into two major categories: (1) the works which concentrated on partner or alliance selection and often provide mathematical models and (2) the works which focused on network level but often they are descriptive and qualitative, and there are a handful of works which provide step wise processes for network building. Thereupon, according to lack of academic efforts which concentrate on network level and provide mathematical tools, this paper tried to (1) focus on network level, (2) investigate qualitative aspects of problem and provide systematic managerial tool, and (3) provide a mathematical decision-making tool which can assess all possible solutions and lead to precise and reliable solution. These three points are the main difference points which crucially distinguished this work from the previous efforts.

The solutions attained from different methods were shown in Figure 8. Indeed, the "weighting method" is easy to use and produce all possible optimal solutions. "Lexicographic" has a high rate of flexibility and can incorporate detailed opinion of DMs through its flexible parameters. Thus, "lexicographic" and "weighting" methods produce very wide range of Pareto optimal solutions and decision on this wide range is difficult. The "global criterion" has only one parameter to set and it is easy to use, but DMs cannot reflect their judgement through this one parameter, and, also, the results of this method are very dependent on the parameter " $P$," whereas different " $P$ " parameter provide totally different and wide solutions. The best methods are "SIMOLP" and "Satisfactory goals" because they are easy to use and provide high-quality solutions in this problem. They also appropriately consider RBV objective as a long-term issue. SIMOLP is an iterative method and some iterations are needed to achieve the solution, whereas "satisfactory goals" reach the solution in one step. Indeed, these two methods are interactive methods which incorporate the DMs preferences interactively, and also, the problem is based on DMs tradeoffs. Thus, the suitable trade-off can be reached through interactive parameter setting. In this problem, the results produced by SIMOLP and "satisfactory goals" was in accordance with the DMs final trade-off, and as, the satisfactory goal was more easy to use and reach the solution in one step it was found as most suitable method for this problem in the case study. In other words, the "satisfactory goal" method is in compliance with nature of the problem and DMs have a suitable sense about its way of achieving solutions. The "satisfactory goal" in combination with one of "weighting" or "lexicographic" methods leads to much appropriate method, because the "weighting" or "lexicographic" method provides a big picture of all solutions and clears the problem space and this knowledge helps the DMs to easily set the parameters of "satisfactory goal" method and find the appropriate solution.

Noticeably, the framework entails a learning process that occurs for the participants in focus groups. Indeed, the decision-maker's points of view were evolved during the process. Moreover, the framework tried to structure the criteria in managers' mind and clarify the ambiguity of the problem. At the early stages of the process, the managers tend to build the network with possible lowest cost and implicitly ignore the long-terms issues but, at the end, their view was moderated and they compromised between two objectives. The cost-based issues that were revealed in TCT theory are more important in temporal networks which were created for performing temporary tasks, whereas long-term issues and RBV objective are more suitable for permanent networks in which the hub tends to form the network based on members' resources and capabilities. In such a network, time limits are not important and the networks formed over times. In this problem, the network is not temporal and also there are time and cost limits and the hub should accomplish the task in a predefined time window. Thus, it is essential to compromise between the two objectives. 
TABLE 5: Selected solution in all methods.

\begin{tabular}{lcccc}
\hline Weighting method & Global criterion & Lexicographic & Satisfactory goals & SIMOLP \\
\hline $0.2 \leq \alpha<0.6$ & $P=1$ & Preferred obj. $=$ RBV, RBV $\geq 2.2$ & TCT $\geq 1.8$ & First iteration solution \\
\hline
\end{tabular}
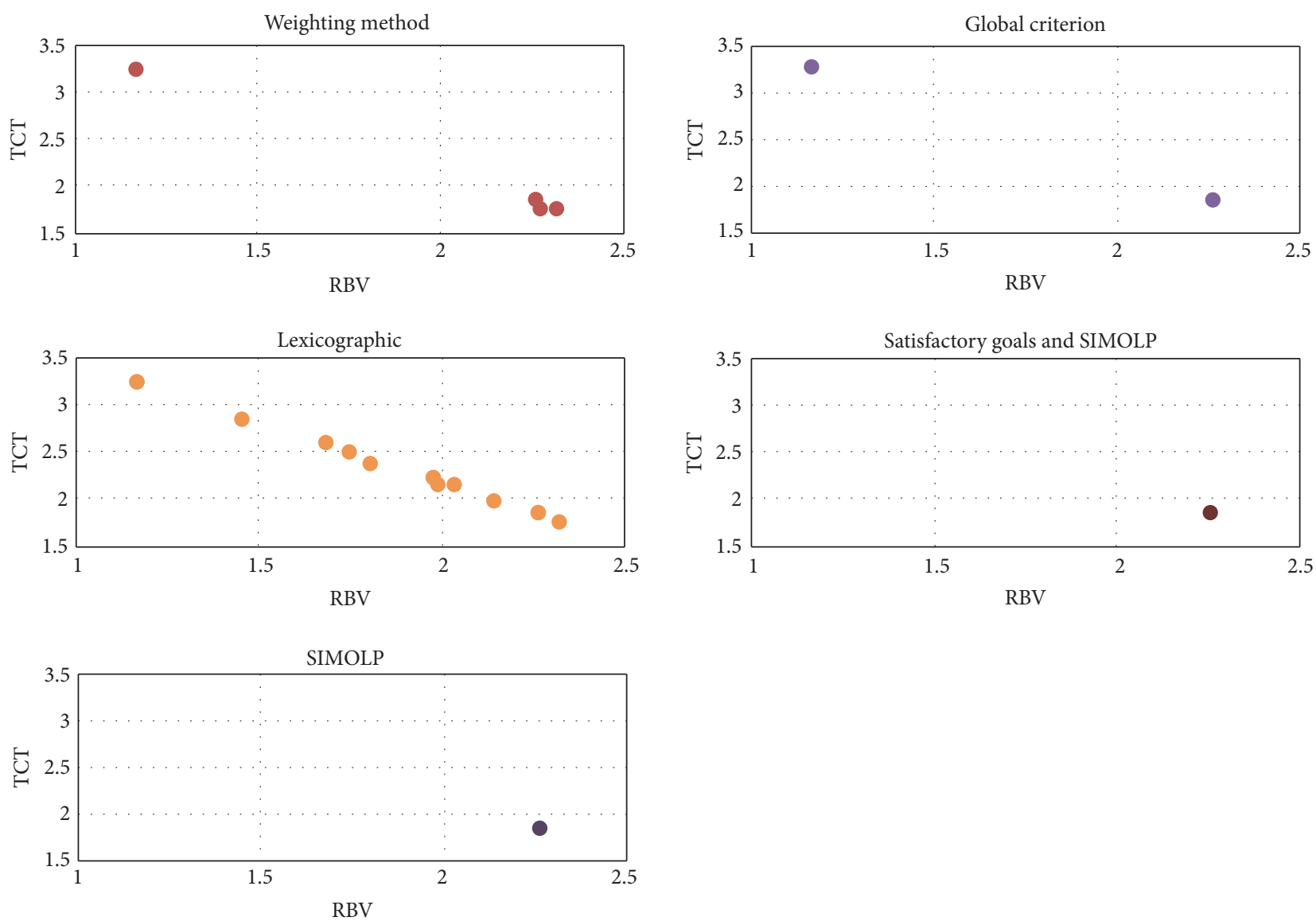

FIGURE 8: Comparison of solutions attained from different methods.

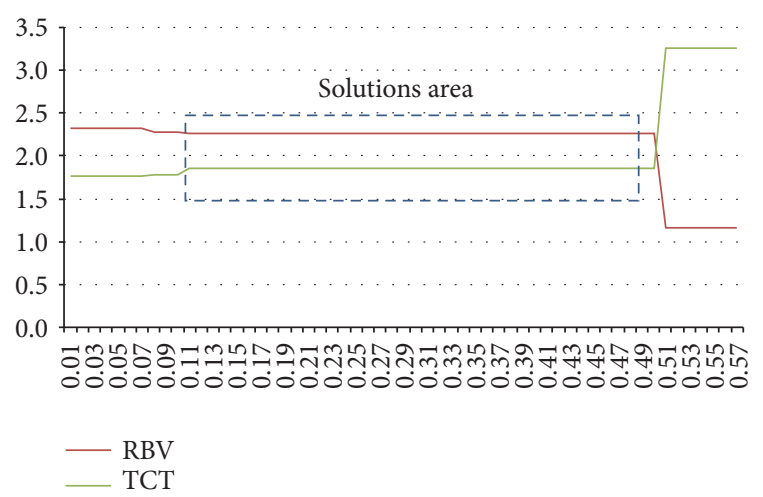

FIGURE 9: RBV and TCT objective values based on different weighting method.

The solutions obtained from the weighting method are shown in Figure 9, and selected solution based on the decision-makers trade-off was illustrated in it. The horizontal axis is the weight (Alpha) and the vertical is the objectives' values. The increase in horizontal axis is equal to increase in alpha and it means that the DMs prefer the TCT objective. In other words, the horizontal axis shows a spectrum in which at one hand the total preference is dedicated to TCT and on the other hand to RBV. It means that the solutions showed on the right-hand side of the figure are equivalent to the solution that is obtained by solving a one objective problem with TCT objective, and the solution illustrated in the left-hand side of the figure is equivalent to solving the problem singly with RBV objective. The selected solution depicts the compromise between two objectives and is strictly different from the solutions related to one objective problem. The selected solution's cost is the second desirable, but its RBV value is much closer to the optimum value. So the DMs accept higher costs to achieve a higher value of RBV objective and this is another justification of the selected solution. The selected solution is achieved by weights between 0.2 and 0.6 .

\section{Conclusions}

This paper provides an analytic method that consists of a hybrid AHP and multiobjective programing and 
a managerial framework for collaborative network building process by structuring the various aspects of the problem in a step by step procedure. In addition, five various multiobjective methods applied to the problem and their performances were compared. The research findings provide a more robust solution for selecting network alternatives on the basis of cost and time and speed of product development. As declared in Discussion, the cost of project reduced significantly in comparison with the plan A of the project (in which the project was conducted internally). This research has made the contributions into two areas, namely, (1) conceptual contribution and (2) methodological contribution.

Conceptual Contribution. This research provides a combinatorial theory of interorganizational relationships. The two contemporary theories of interorganizational relationships were combined. The first is the transaction cost theory which stands for short-term and financial benefits of firm, and the second is resource-based theory that stands for the longterm and nonfinancial benefits of firms. On one hand, the managers tend to accomplish their tasks with lowest possible cost and on the other hand they prefer to maintain their long-term advantages by developing sustainable capabilities which are in contrast to low-cost decisions. The outcome of the combination is more robust as it complements the weaknesses of the individual theories.

Methodological Contribution. The research proposes a mathematical model combining AHP and multiobjective programming with the aim to structure the various aspects of the problem and to model it in a systematic way. One important advantage of the framework is that it tries to provide a holistic solution for a firm's portfolio of relations, instead of optimizing it at a dyadic level. This is important because a piecemeal approach to solving each independent relation would restrict optimum solution. Also, a holistic solution overcomes the phenomenon of lock-in and lock-out effect that arises due to the presence of one or more dyadic relationships in the system. Secondly, the mathematical model is a hybrid AHP and multiobjective programming model which considers time, cost, and the internal relation of activities. The model made it possible to consider all possible solutions systematically and to be assured that selected solution is the best one based on available knowledge.

6.1. Limitations and Future Research Directions. Although this research contributes to the network formation literature, it has some limitations. First, the most important limitation of this research is about generalization. The proposed framework was implemented in a case study in IT industry, but it needs to be strengthened in other longitudinal studies, other case studies, and in other cross-industry studies. Second, the framework needs a huge volume of data that should be provided by participant experts. Although the network formation problem is a critical and long-term decision and this volume of data is completely logical, it causes boredom of participants and consequently decreases the data accuracy. Third, although a hybrid theory of RBV and TCT was employed in the framework, more efforts are needed to establish a new, comprehensive, hybrid theory; and there are many justifications and implications that should be discussed in the new hybrid theory. Forth, although the effects of the relationships on each other were considered on the model, the more dynamic analysis can be done in the future works. One of the research directions for the future works is to employ fuzzy variables in the model to control the ambiguity of the data. Another research direction is to do deep longitudinal and multiple case studies to strength it and discuss the generalizability of the model. Furthermore, the hybrid theory of TCT and RBV can be employed for governance of the interorganizational relationships and not just for formation phase.

\section{Competing Interests}

The authors declare that there are no competing interests regarding the publication of this paper.

\section{References}

[1] R. Gulati, N. Nohria, and A. Zaheer, "Strategic networks," Strategic Management Journal, vol. 21, no. 3, pp. 203-215, 2000.

[2] J. Tikkanen and A. Halinen, Network Approach to Strategic Management-Exploration to the Emerging Perspective, 2003.

[3] K. Möller, A. Rajala, and S. Svahn, "Strategic business netstheir type and management," Journal of Business Research, vol. 58, no. 9, pp. 1274-1284, 2005.

[4] L. M. Camarinha-Matos and H. Afsarmanesh, "Collaborative networks: a new scientific discipline," Journal of Intelligent Manufacturing, vol. 16, no. 4-5, pp. 439-452, 2005.

[5] L. M. Camarinha-Matos, H. Afsarmanesh, N. Galeano, and A. Molina, "Collaborative networked organizations-concepts and practice in manufacturing enterprises," Computers \& Industrial Engineering, vol. 57, no. 1, pp. 46-60, 2009.

[6] J. H. Dyer and H. Singh, "The relational view: cooperative strategy and sources of interorganizational competitive advantage," Academy of Management Review, vol. 23, no. 4, pp. 660-679, 1998.

[7] K. K. Möller and A. Halinen, "Business relationships and networks: managerial challenge of network era," Industrial Marketing Management, vol. 28, no. 5, pp. 413-427, 1999.

[8] B. Axelsson and G. Easton, Industrial Networks: A New View of Reality, Routledge, London, UK, 1992.

[9] I. Snehota and H. Hakansson, Developing Relationships in Business Networks, Routledge Londres, 1995.

[10] A. Parmigiani and M. Rivera-Santos, "Clearing a path through the forest: a meta-review of interorganizational relationships," Journal of Management, vol. 37, no. 4, pp. 1108-1136, 2011.

[11] T. H. Davenport, M. Leibold, and S. C. Voelpel, Strategic Management in the Innovation Economy: Strategic Approaches and Tools for Dynamic Innovation Capabilities, John Wiley \& Sons, New York, NY, USA, 2007.

[12] D. J. Brass, J. Galaskiewicz, H. R. Greve, and W. Tsai, "Taking stock of networks and organizations: a multilevel perspective," Academy of Management Journal, vol. 47, no. 6, pp. 795-817, 2004.

[13] T. Ritter, I. F. Wilkinson, and W. J. Johnston, "Managing in complex business networks," Industrial Marketing Management, vol. 33, no. 3, pp. 175-183, 2004. 
[14] L. M. Camarinha-Matos and H. Afsarmanesh, "Classes of collaborative networks," in Encyclopedia of Networked and Virtual Organizations, Information Science Reference, 2008.

[15] J. C. Jarillo, “On strategic networks," Strategic Management Journal, vol. 9, no. 1, pp. 31-41, 1988.

[16] T. E. Stuart and O. Sorenson, "Strategic networks and entrepreneurial ventures," Strategic Entrepreneurship Journal, vol. 1, no. 3-4, pp. 211-227, 2007.

[17] M. Kohtamäki, S. Thorgren, and J. Wincent, "Organizational identity and behaviors in strategic networks," Journal of Business \& Industrial Marketing, vol. 31, no. 1, pp. 36-46, 2016.

[18] B. Tan, "Modelling and analysis of a network organization for cooperation of manufacturers on production capacity," Mathematical Problems in Engineering, vol. 2006, Article ID 85103, 24 pages, 2006.

[19] S. C. Henneberg, S. Mouzas, and P. Naudé, "Network pictures: concepts and representations," European Journal of Marketing, vol. 40, no. 3-4, pp. 408-429, 2006.

[20] K. Möller and A. Rajala, "Rise of strategic nets-new modes of value creation," Industrial Marketing Management, vol. 36, no. 7, pp. 895-908, 2007.

[21] S. Mouzas, S. Henneberg, and P. Naudé, "Developing network insight," Industrial Marketing Management, vol. 37, no. 2, pp. 167-180, 2008.

[22] F. Cruijssen, P. Borm, W. Dullaert, and H. Hamers, "A versatile framework for cooperative hub network development," European Journal of Industrial Engineering, vol. 4, no. 2, pp. 210-227, 2010.

[23] J. Partanen and K. Möller, "How to build a strategic network: a practitioner-oriented process model for the ICT sector," Industrial Marketing Management, vol. 41, no. 3, pp. 481-494, 2012.

[24] N. J. Pulles, J. Veldman, and H. Schiele, "Identifying innovative suppliers in business networks: An Empirical Study," Industrial Marketing Management, vol. 43, no. 3, pp. 409-418, 2014.

[25] M. Nippa, S. Beechler, and A. Klossek, "Success factors for managing international joint ventures: a review and an integrative framework," Management and Organization Review, vol. 3, no. 2, pp. 277-310, 2007.

[26] W. Shi, J. Sun, and J. E. Prescott, "A temporal perspective of merger and acquisition and strategic alliance initiatives: review and future direction," Journal of Management, vol. 38, no. 1, pp. 164-209, 2012.

[27] J. Christoffersen, "A review of antecedents of international strategic alliance performance: synthesized evidence and new directions for core constructs," International Journal of Management Reviews, vol. 15, no. 1, pp. 66-85, 2013.

[28] J. R. Brown, A. S. Krishen, and C. S. Dev, "The role of ownership in managing interfirm opportunism: a dyadic study," Journal of Marketing Channels, vol. 21, no. 1, pp. 31-42, 2014.

[29] E. Gomes, B. R. Barnes, and T. Mahmood, "A 22 year review of strategic alliance research in the leading management journals," International Business Review, vol. 25, no. 1, pp. 15-27, 2016.

[30] P. C. van Fenema and C. Loebbecke, "Towards a framework for managing strategic tensions in dyadic interorganizational relationships," Scandinavian Journal of Management, vol. 30, no. 4, pp. 516-524, 2014.

[31] J. M. Whipple, R. Wiedmer, and K. K. Boyer, "A dyadic investigation of collaborative competence, social capital, and performance in buyer-supplier relationships," Journal of Supply Chain Management, vol. 51, no. 2, pp. 3-21, 2015.
[32] B.-G. Son, C. Kocabasoglu-Hillmer, and S. Roden, "A dyadic perspective on retailer-supplier relationships through the lens of social capital," International Journal of Production Economics, vol. 178, pp. 120-131, 2016.

[33] D. Lavie, "Alliance portfolios and firm performance: a study of value creation and appropriation in the U.S. software industry," Strategic Management Journal, vol. 28, no. 12, pp. 1187-1212, 2007.

[34] P. Ozcan and K. M. Eisenhardt, "Origin of alliance portfolios: entrepreneurs, network strategies, and firm performance," Academy of Management Journal, vol. 52, no. 2, pp. 246-279, 2009.

[35] T. J. Vapola, M. Paukku, and M. Gabrielsson, "Portfolio management of strategic alliances: an international business perspective," International Business Review, vol. 19, no. 3, pp. 247-260, 2010.

[36] U. Wassmer, "Alliance portfolios: a review and research agenda," Journal of Management, vol. 36, no. 1, pp. 141-171, 2010.

[37] I. Castro, C. Casanueva, and J. L. Galán, "Dynamic evolution of alliance portfolios," European Management Journal, vol. 32, no. 3, pp. 423-433, 2014.

[38] J. Schmutzler, R. Gutiérrez, E. Reficco, and P. Márquez, "Evolution of an alliance portfolio to develop an inclusive business," in Social Partnerships and Responsible Business: A Research Handbook, pp. 143-163, 2014.

[39] R. Gutiérrez, P. Márquez, and E. Reficco, "Configuration and development of alliance portfolios: a comparison of same-sector and cross-sector partnerships," Journal of Business Ethics, vol. 135, no. 1, pp. 55-69, 2016.

[40] S. Haider and F. Mariotti, "The orchestration of alliance portfolios: the role of alliance portfolio capability," Scandinavian Journal of Management, vol. 32, no. 3, pp. 127-141, 2016.

[41] U. Lichtenthaler, "Alliance portfolio capability: a conceptual framework for the role of exploration or exploitation alliances," Journal of Strategy and Management, vol. 9, no. 3, pp. 281-301, 2016.

[42] H. Håkansson and I. Snehota, "No business is an island: the network concept of business strategy," Scandinavian Journal of Management, vol. 5, no. 3, pp. 187-200, 1989.

[43] K. Möller, "Theory map of business marketing: relationships and networks perspectives," Industrial Marketing Management, vol. 42, no. 3, pp. 324-335, 2013.

[44] Y. Bramoullé, R. Kranton, and M. D’Amours, "Strategic interaction and networks," The American Economic Review, vol. 104, no. 3, pp. 898-930, 2014.

[45] J. Popp, G. MacKean, A. Casebeer, H. Milward, and R. Lindstrom, Inter-Organizational Networks: A Review of the Literature to Inform Practice, Collaborating Across Boundaries Series, IBM Center for the Business of Government, Washington, DC, USA, 2014.

[46] H. Hoang and A. Yi, "Network-based research in entrepreneurship: a decade in review," Foundations and Trends in Entrepreneurship, vol. 11, no. 1, pp. 1-54, 2015.

[47] B. R. Barringer and J. S. Harrison, "Walking a tightrope: creating value through interorganizational relationships," Journal of Management, vol. 26, no. 3, pp. 367-403, 2000.

[48] J. H. Dyer, "Effective interfirm collaboration: how firms minimize transaction costs and maximize transaction value," Strategic Management Journal, vol. 18, no. 7, pp. 535-556, 1997.

[49] A. Madhok and S. B. Tallman, "Resources, transactions and rents: managing value through interfirm collaborative relationships," Organization Science, vol. 9, no. 3, pp. 326-339, 1998. 
[50] O. E. Williamson, "Comparative economic organization: the analysis of discrete structural alternatives," Administrative Science Quarterly, vol. 36, no. 2, pp. 269-296, 1991.

[51] T. K. Das and B.-S. Teng, "A resource-based theory of strategic alliances," Journal of Management, vol. 26, no. 1, pp. 31-61, 2000.

[52] M. J. Leiblein and D. J. Miller, "An empirical examination of transaction-and firm-level influences on the vertical boundaries of the firm," Strategic Management Journal, vol. 24, no. 9, pp. 839-859, 2003.

[53] T. R. Holcomb and M. A. Hitt, "Toward a model of strategic outsourcing," Journal of Operations Management, vol. 25, no. 2, pp. 464-481, 2007.

[54] E. T. Penrose, The Theory oi the Growth oi the Firm, John Wiley \& Sons, New York, NY, USA, 1959.

[55] B. Wernerfelt, "A resource-based view of the firm," Strategic Management Journal, vol. 5, no. 2, pp. 171-180, 1984.

[56] J. Barney, "Firm resources and sustained competitive advantage," Journal of Management, vol. 17, no. 1, pp. 99-120, 1991.

[57] D. J. Teece, G. Pisano, and A. Shuen, "Dynamic capabilities and strategic management," Strategic Management Journal, vol. 18, no. 7, pp. 509-533, 1997.

[58] K. Hafeez, Y. Zhang, and N. Malak, "Determining key capabilities of a firm using analytic hierarchy process," International Journal of Production Economics, vol. 76, no. 1, pp. 39-51, 2002.

[59] K. Hafeez, Y. Zhang, and N. Malak, "Core competence for sustainable competitive advantage: a structured methodology for identifying core competence," IEEE Transactions on Engineering Management, vol. 49, no. 1, pp. 28-35, 2002.

[60] J. Kraaijenbrink, J.-C. Spender, and A. J. Groen, “The resourcebased view: a review and assessment of its critiques," Journal of Management, vol. 36, no. 1, pp. 349-372, 2010.

[61] E. W. K. Tsang, "Transaction cost and resource-based explanations of joint ventures: a comparison and synthesis," Organization Studies, vol. 21, no. 1, pp. 215-242, 2000.

[62] O. E. Williamson, "Strategy research: governance and competence perspectives," Strategic Management Journal, vol. 20, no. 12, pp. 1087-1108, 1999.

[63] W. Yue, Y. Wang, and C. Dai, "An evolutionary algorithm for multiobjective fuzzy portfolio selection models with transaction cost and liquidity," Mathematical Problems in Engineering, vol. 2015, Article ID 569415, 15 pages, 2015.

[64] K. M. Eisenhardt and C. B. Schoonhoven, "Resource-based view of strategic alliance formation: strategic and social effects in entrepreneurial firms," Organization Science, vol. 7, no. 2, pp. 136-150, 1996.

[65] F. David, L.-E. Gadde, and S. Ivan, Managing Business Relationship, John Wiley \& Sons, West Sussex, UK, 1998.

[66] F. R. Dwyer, P. H. Schurr, and S. Oh, "Developing buyer-seller relationships," Journal of Marketing, vol. 51, no. 2, pp. 11-27, 1987.

[67] A. Larson, "Network dyads in entrepreneurial settings: a study of the governance of exchange relationships," Administrative Science Quarterly, vol. 37, no. 1, pp. 76-104, 1992.

[68] D. T. Wilson, "An integrated model of buyer-seller relationships," Journal of the Academy of Marketing Science, vol. 23, no. 4, pp. 335-345, 1995.

[69] I. Abosag and P. Naudé, "Development of special forms of B2B relationships: examining the role of interpersonal liking in developing Guanxi and Et-Moone relationships," Industrial Marketing Management, vol. 43, no. 6, pp. 887-896, 2014.
[70] A. V. Gumerov, L. E. Fatikhova, K. O. Kolpakov et al., "Features of forming an interaction network of an entrepreneurial structure," Review of European Studies, vol. 7, no. 4, pp. 209-215, 2015.

[71] S. Lacoste and R. E. Johnsen, "Supplier-customer relationships: a case study of power dynamics," Journal of Purchasing and Supply Management, vol. 21, no. 4, pp. 229-240, 2015.

[72] T. Mandják, Z. Szalkai, E. Neumann-Bódi, M. Magyar, and J. Simon, “Emerging relationships: how are they born?" Industrial Marketing Management, vol. 49, pp. 32-41, 2015.

[73] T. Mandják, Z. Szalkai, E. Neumann-Bódi, M. Magyar, and J. Simon, "Trigger issues in emerging relationships," Industrial Marketing Management, vol. 58, pp. 137-147, 2016.

[74] P. Hennelly and C. Y. Wong, "The formation of new inter-firm relationships: a UK offshore wind sector analysis," International Journal of Energy Sector Management, vol. 10, no. 2, pp. 172-190, 2016.

[75] M. Ebers, "Explaining inter-organizational network formation," The Formation of Inter-Organizational Networks, vol. 1, pp. 3-40, 1997.

[76] P. A. David and L. C. Keely, "The economics of scientific research coalitions: collaborative network formation in the presence of multiple funding agencies," in Science and Innovation: Rethinking the Rationales for Funding and Governance, pp. 251-308, Edward Elgar Publishing, Cheltenham, UK, 2003.

[77] A. Hinterhuber, "Value chain orchestration in action and the case of the global agrochemical industry," Long Range Planning, vol. 35, no. 6, pp. 615-635, 2002.

[78] M. A. Gaspar, R. S. Silva, M. C. Farina, and J. P. L. de Siqueira, "Inter-organizational relationships: promoters and restrictive factors in the formation of cooperation network," Revista Eletrônica de Estratégia \& Negócios, vol. 7, no. 1, pp. 213-241, 2014.

[79] A. Hale and L. White, "Developing a framework to establish collaborative enterprise networks," in Proceedings of the 8th Annual IEEE International Systems Conference (SysCon '14), pp. 431-438, IEEE, Ottawa, Canada, April 2014.

[80] A. Jussila, T. Mainela, and S. Nätti, "Formation of strategic networks under high uncertainty of a megaproject," Journal of Business \& Industrial Marketing, vol. 31, no. 5, pp. 575-586, 2016.

[81] J. Zhang and A. Pezeshkan, "Host country network, industry experience, and international alliance formation: evidence from the venture capital industry," Journal of World Business, vol. 51, no. 2, pp. 264-277, 2016.

[82] K. Keahey, I. Foster, T. Freeman, and X. Zhang, "Virtual workspaces: achieving quality of service and quality of life in the Grid," Scientific Programming, vol. 13, no. 4, pp. 265-275, 2005.

[83] M. H. Danesh, B. Raahemi, S. A. Kamali, and G. Richards, "A framework for process and performance management in service oriented virtual organisations," International Journal of Computer Information Systems and Industrial Management Applications, vol. 5, pp. 203-215, 2013.

[84] J. Crispim, N. Rego, and J. Pinho de Sousa, "Stochastic partner selection for virtual enterprises: a chance-constrained approach," International Journal of Production Research, vol. 53, no. 12, pp. 3661-3677, 2015.

[85] W. Lin, W. Wu, and J. Z. Wang, "A heuristic task scheduling algorithm for heterogeneous virtual clusters," Scientific Programming, vol. 2016, Article ID 7040276, 10 pages, 2016.

[86] M. E. Porter, “Competitive strategy," Measuring Business Excellence, vol. 1, no. 2, pp. 12-17, 1997. 
[87] C. Parolini, The Value Net: A Tool for Competitive Strategy, Wiley, Chichester, UK, 1999.

[88] K. Hafeez, Y. Zhang, and N. Malak, "Identifying core competence," IEEE Potentials, vol. 21, no. 2, pp. 2-7, 2002.

[89] K. Hafeez, N. Malak, and Y. B. Zhang, "Outsourcing noncore assets and competences of a firm using analytic hierarchy process," Computers and Operations Research, vol. 34, no. 12, pp. 3592-3608, 2007.

[90] P. Fiala, "An ANP/DNP analysis of economic elements in today's world network economy," Journal of Systems Science and Systems Engineering, vol. 15, no. 2, pp. 131-140, 2006.

[91] E. Deelman, G. Singh, M.-H. Su et al., "Pegasus: a framework for mapping complex scientific workflows onto distributed systems," Scientific Programming, vol. 13, no. 3, pp. 219-237, 2005.

[92] C.-L. Hwang and A. S. M. Masud, in Multiple Objective Decision Making_Methods and Applications, Springer, Berlin, Germany, 1979.

[93] J. Branke, K. Deb, K. Miettinen, and R. Slowiński, Eds., Multiobjective Optimization: Interactive and Evolutionary Approaches, vol. 5252 of Theoretical Computer Science and General Issues, Springer Science \& Business Media, 2008.

[94] G. R. Reeves and L. S. Franz, "A simplified interactive multiple objective linear programming procedure," Computers \& Operations Research, vol. 12, no. 6, pp. 589-601, 1985. 

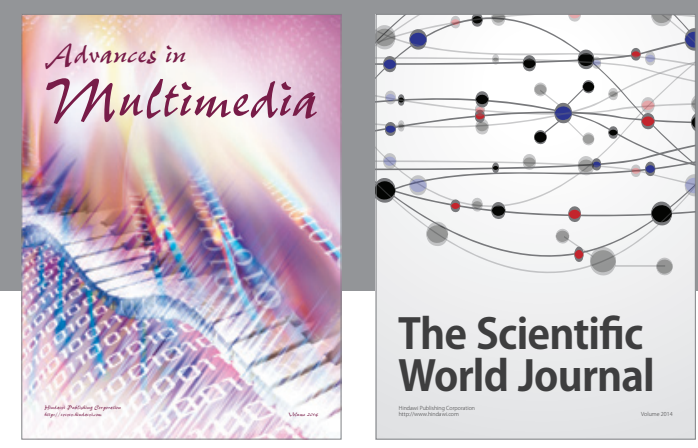

The Scientific World Journal
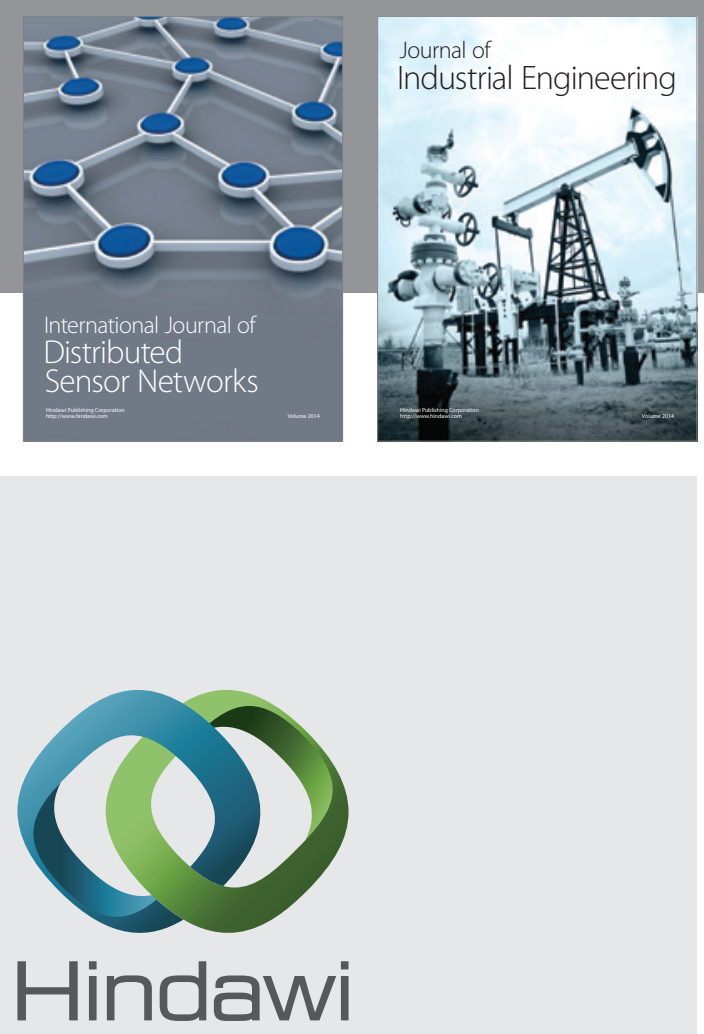

Submit your manuscripts at

http://www.hindawi.com

\section{Computer Networks} and Communications
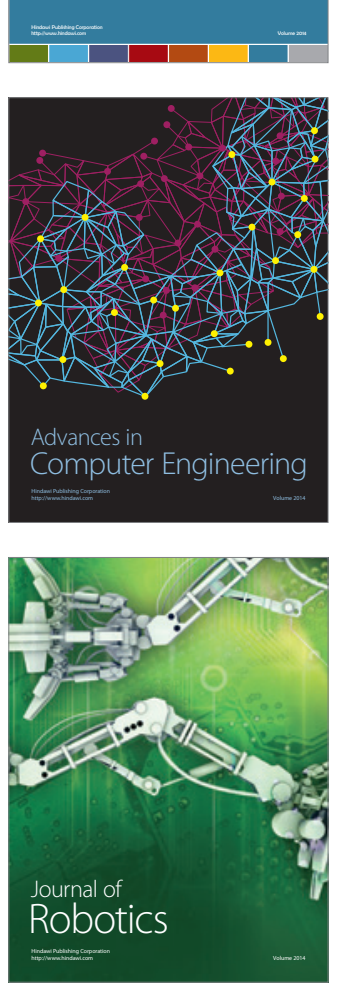
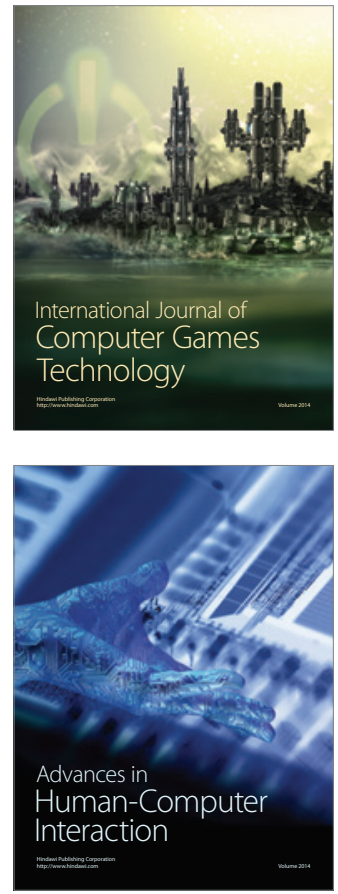
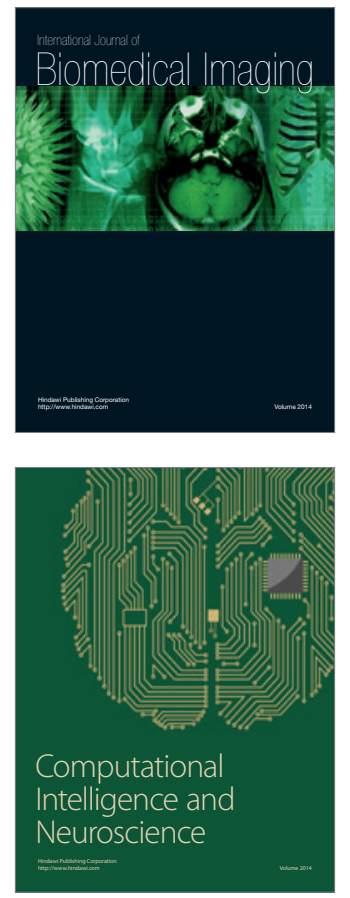
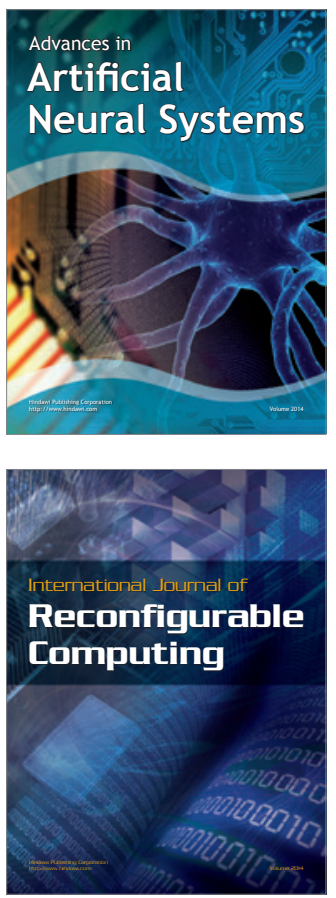
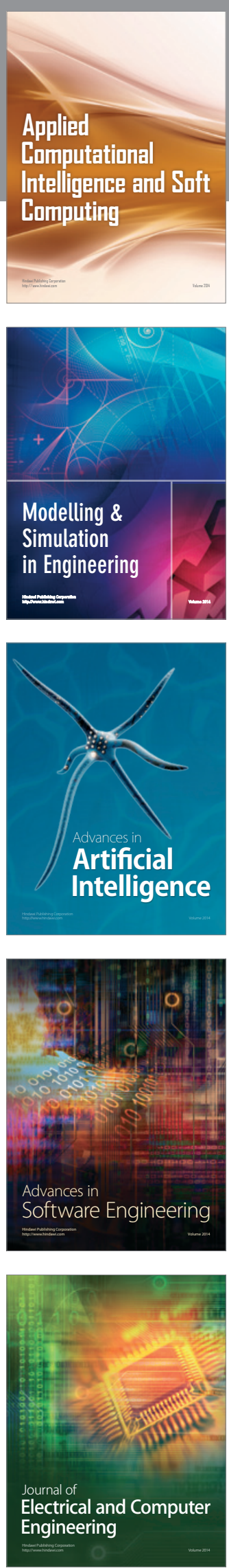